\title{
Investigation of Structure of Technology Cycle Time of Hydraulic Manipulators in the Process of Loading Forwarders with Logs
}

\author{
Maxim Piskunov
}

\begin{abstract}
In the practice of using cut-to-length technology, hydraulic manipulators are widely used. Understanding manipulator cycle is important for improving existing logging technologies and developing new machine designs. The paper analyzes structure of technological cycle and operating time of manipulator in the process of loading forwarder on skid trails. Twenty-one loading processes were investigated. In the structure of technological cycle, the following elements were considered: empty movements, loaded movements, movements of manipulator links when performing operations inside load space of forwarder and special techniques such as re-grabbing logs and pulling of an incompletely closed log grip through the logs when the ends of the grabbed logs tilt and abut against the ground used during loading movement. Statistical processing of data showed that median values of samples consisting of time intervals of empty movements are in trange from 3.8 to 6 seconds, the median of samples of loaded movements is 6-16 seconds and median of samples of a pair of movements 5-9 seconds. With a 95\% degree of probability, under the studied production conditions, the time of one loaded movement falls within the range of 4-14 seconds; one empty movement - in the range of 3-7 seconds. Total time of empty movements takes a share from 20 to $45 \%$ of the total loading time (on average $30 \%$ ), the total time of loading movements is from 51 to $72 \%$ (on average $63 \%$ ), the time of operations inside the load space is from 0 to $18 \%$ (on average $7 \%$ ). Time of loaded movements, including use of special techniques, is from 13\% to $64 \%$ of total time of loaded movements (or 10-53\% of total number of loaded movements). The time, consisting of a pair of movements: empty and loaded, is somewhat influenced by forwarder size. Duration of one loaded movement is significantly affected by use of special techniques by the operator. Number and duration of loaded movements with these techniques is significantly influenced by: average size of loaded assortments and number of assortments carried in the grapple during one loaded movement. No significant influence of average size of assortments, number of assortments in grapple and size of the machine on empty movements was found. However, some influence on empty movements of number of loaded movements performed from one forwarder parking lot was observed. Duration and frequency of operations within the load space are weakly correlated with the size of assortments and forwarder size.
\end{abstract}

Keywords: hydraulic manipulator, cut-to-length technology, forwarder, time, technology cycle

\section{Introduction}

Recently, hydraulic manipulators have been widely used as processing equipment in the logging process. In many forestry regions, the predominant technology in the timber harvesting process is cut-to-length technology (Spinelli et al. 2011, Malinen et al. 2016, Moskalik et al. 2017, Lundback et al. 2018). As a rule, when harvesting wood using this technology, chainsaw or harvesters are used for felling trees and forwarders equipped with manipulators are used for skidding. Loading and unloading works, carried out 
only with the help of a hydraulic manipulator, account for a significant part in the structure of the technological cycle of the forwarder.

Previous studies displayed that the share of loading is $35-45 \%$, unloading $23-32 \%$ of the total forwarder working cycle time with an average skidding distance of 650-729 m (Proto et al. 2018); loading 35\% (on average), unloading 31\%, with an average distance of 306 and $597 \mathrm{~m}$ (Proto et al. 2017); loading 42\%, unloading $18 \%$, with an average distance of $428 \mathrm{~m}$ (Strandgard et al. 2017); loading and unloading $71 \%$, with an average distance of $97 \mathrm{~m}$ (Ghaffarian et al. 2007). In the studies carried out, the loading time includes the time spent by the forwarder on the movement along the trail between the stops at which the assortments are loaded.

Researchers also report that manipulator work accounts for $74.8 \%$ of the total loading time in a process, in which forwarder loading time is $45 \%$, unloading time is $19 \%$ of the total forwarder effective operation time, and the average skidding distance is $219 \mathrm{~m}$. (Manner et al. 2016). Significant proportion of manipulator run time (about $65 \%$ ) of the total forwarder cycle time is reported by Puttock et al. 2005.

Technological cycle of the hydraulic manipulator during the loading of timber-trailed units with assortments in stacks was investigated by Smirnov and Bakulina 2013. Four operations are distinguished in the technological cycle of loading: empty movement, grapple guidance and grabbing of assortments, moving assortments, stacking. The share of these operations in the cycle structure was within 15.1-23.7\%, $18.7-29.9 \%, 22.7-44.8 \%$ and $14.4-36.7 \%$, respectively.

Study of the working cycles of two forwarders operated by two different operators, but with the same operating experience, showed approximately the same proportion of loading (and unloading) in two different cycles (Dvorak et al. 2008): loading 55-57\%, unloading $28-30 \%$. The study indirectly confirms the presence of constant parameters in the operating cycle of the manipulator, which do not depend on external factors. Data confirming that harvesting wood using a harvester reduces the loading time (operating time of the manipulator) of the forwarder in comparison with the technology of harvesting using chainsaws, are presented in the works of Laitila et al. 2007, Danilović et al. 2014.

Results of a study of the influence of such factors as the number of assortments in a load and total log concentration on the operating time of the forwarder are presented in the work of Manner et al. 2013. Among other elements of the general structure of the forwarder's working cycle, the following elements are considered - time consumption for a loading (an unloading) manipulator cycle. As a number of assortments in a load increases, the average manipulator cycle time increases. When loading (unloading) one type of assortment in a batch, the average time was $0.24(0.27) \mathrm{min} /$ cycle, two types $0.27(0.34)$, three types $0.29(0.51), 5$ types of assortments $0.35(0.6)$.

The influence of the size class of a forwarder on time consumption of timber loading (unloading) by the hydraulic manipulator is discussed in the work of Stankić et al. 2012, who presented linear models of loading time for a forwarder using a manipulator (min/turn) depending on the number of loaded assortments. For the heavy class of forwarders (carrying capacity from 14 tons), the loading time is shorter than for the middle class (carrying capacity 12 tons) with the same number of loaded assortments. Differences increase with the number of loaded assortments. For unloading, asymptotic dependences are presented, showing a much less pronounced dependence of time on the class of the forwarder.

The average share of the manipulator operating time in the overall structure of the forwarder's operating time (Hildt et al. 2019) was: for heavy forwarders $62.1 \%$ (including $33.7 \%$ loading); for medium $59.5 \%$ (34.4\%); for light $62.3 \%(39.1 \%)$, with an average distance of transportation of assortments of $313 \mathrm{~m}, 229 \mathrm{~m}$ and $303 \mathrm{~m}$, respectively. Findings show some tendency to reduce the proportion of time spent on manipulator operation when loading a forwarder, in the general structure of the forwarder's working cycle, with an increase in the class of the machine, but during unloading, the opposite trend is noted, which generally equalizes the performance of the manipulator for machines of different classes. Loading time increases depending on the class of the forwarder (due to the increase in the size of the load space). The increase in the average size of the loaded log reduces the cycle time of the manipulator when loading, and a logarithmic dependence is offered to describe this relationship.

On the basis of experimental data, linear regressions of loading time $\left(\mathrm{cmin} / \mathrm{m}^{3}\right)$ were constructed depending on the volume of load and the number of loaded assortments (average number of 47 pieces (30-82)) and unloading time depending on the volume of load (Strandgard et al. 2017). For loading, the coefficient of determination was $64 \%$, for unloading $27 \%$. Such values of the coefficients indicate the presence of additional factors that were not considered in the models, but could affect the parameters under study.

Researchers (Nurminen et al. 2006) distinguish elements in the structure of the forwarder cycle: loading and unloading, within which the manipulator 
operates. For the loading cycle, depending on the type of felling: final fellings or thinnings, two different models are offered that link timber volume at the loading stop $\left(\mathrm{m}^{3}\right)$ and the time spent on loading one cubic meter of timber $\left(\mathrm{min} / \mathrm{m}^{3}\right)$. Models have the form of inverse dependencies.

The models offered by the researchers are considered in the context of studying the overall performance of the forwarder, based on some averaged characteristics. In this connection, the actual influence of the investigated factors or their combination is not fully manifested in these models, but indicates a fundamental tendency. The wide spread of data obtained by researchers in the course of experiments is an indirect confirmation of this thesis. A more detailed study of a separate technological cycle of the manipulator will reveal the influence of new factors or clarify the degree of influence of already known factors or their combination on the operating cycle of the forwarder as a whole, because the work of the manipulator in the general technological cycle of the forwarder occupies a significant place.

In addition to studying the influence of various factors on the effective operation time of the forwarder and on individual elements of the forwarder's technological cycle, there are a number of works in which the authors published the results of research on various aspects of manipulator automation. For example, studies were conducted on the use of the boom tip control system (BTC) (another name for the Intelligent Boom Control (IBC) - John Deere 2020) to control the manipulator (Manner et al. 2017). Some advantages of using this system in comparison with the conventional manipulator control system of conventional boom control (CBC) were outlined.

The difference between IBC and $\mathrm{CBC}$ is as follows: »In IBC, the left joystick's back-forth actuation controls the horizontal distance between the boom tip and the crane pillar (moves the boom tip horizontally towards or away from the manipulator pillar), while the right joystick's back-forth actuation controls the boom tip vertical position (height) « Manner et al. 2017. »With the conventional boom control (CBC), the operator manually controls each of the independent boom joint movements and combines them to achieve a desired boom tip movement« Manner et al. 2017.

Experimental platforms for testing control systems and algorithms for planning movements of manipulator links in real time are described in a study by Ortiz Morales et al. 2014. It also provides an overview of the trajectory planning algorithm and the manipulator motion control method.
The importance of automation of manipulator control is noted in the article by La Hera and Ortiz Morales 2019. The authors provide information obtained from motion sensors installed on manipulator joints. The data from the sensors allowed the researchers to obtain information about the patterns of the operator's control of the movements of the manipulator links: about the trajectories of the links, and about influence of operator settings on motion parameters. Authors emphasize that these results cannot be used as final conclusions, but they are useful for analyzing what the link motion parameter detection technology demonstrates. This information is also useful for analyzing both directions of increasing the efficiency of the manipulator, and ways of improving the automation system of the manipulator.

Review of articles confirms that the study of the features of the technological cycle of the manipulator and the analysis of the factors influencing the cycle is an important task for understanding the structure of the forwarder's working time in general. It is advisable to consider the manipulator as a separate technological machine that functions in the structure of the forwarder's technological process. The purpose of the article is to analyze the composition of the technological cycle of the forwarder manipulator and to analyze the factors that affect the duration of the individual elements of this cycle.

\section{Materials and Methods}

Work of different models of forwarders, loading assortments into the load space on skid trails, was investigated. Recording of the forwarders' work in production conditions was carried out using a digital camera installed on board the machine. The camera was installed in such a way that the moving grapple always fell into the camera lens. The video recording began from the moment the empty forwarder began to move along the skid trail and stopped after the forwarder's load space was fully loaded. The preliminary adaptation of the working area and the working parameters of the machine were not carried out, meaning that a fragment of the real work was recorded with all the features. Data for analysis was extracted from the obtained video recordings.

Each forwarder examined carried out loading on a skid trail after the final harvesting of the harvester in clear felling. Management was carried out by different operators who had at least three years of experience with this model of forwarder. Logging was carried out either in a period without snow cover or in conditions of light snow cover that did not affect loading. All areas 
Table 1 Working conditions for forwarders

\begin{tabular}{|c|c|c|c|c|c|c|}
\hline Sample & Model & Region & Average diameter, m & Type of logs & Tree species & Range of lengths, $\mathrm{m}$ \\
\hline S1 & JD 1910E & Sweden, Evleborg & 0.12 & pulpwood & spruce & $4-5$, single 6 \\
\hline S2 & JD 1910E & Sweden, Evleborg & 0.11 & pulpwood & spruce, pine & $4.5-5.5$ \\
\hline S3 & JD 1910E & Sweden, Evleborg & 0.12 & pulpwood & spruce & 5 , single 4.5 and 5.5 \\
\hline S4 & JD 1910E & Sweden, Evleborg & 0.18 & sawlogs & spruce & $4.5-5$ \\
\hline S5 & JD 1910G & Sweden, Evleborg & 0.19 & sawlogs & spruce & $4-4.5$ \\
\hline S6 & JD 1910G & Sweden, Evleborg & 0.18 & sawlogs & spruce, & $4-5.5$ \\
\hline S7 & JD 1910G & Russia, Karelia & 0.17 & sawlogs & spruce, pine & 4 \\
\hline S8 & JD 1910G & Russia, Karelia & 0.14 & pulpwood & birch & $3.5-4.5$ \\
\hline S9 & Ponsse Buffalo & Russia, Karelia & 0.26 & sawlogs & spruce & 5.5 \\
\hline S10 & Ponsse Buffalo & Russia, Karelia & 0.25 & sawlogs & spruce & $3.5-5$ \\
\hline S11 & Ponsse Buffalo & Finland, North Karelia & 0.25 & sawlogs & spruce, pine & $5.5-4.5$ \\
\hline S12 & Ponsse Buffalo & Russia, Karelia & 0.2 & sawlogs & spruce, pine & $3.5-4.5$ \\
\hline S13 & Ponsse Buffalo & Russia, Karelia & 0.14 & pulpwood & spruce & average 5 \\
\hline S14 & Ponsse Buffalo & Finland, South Karelia & 0.27 & sawlogs & spruce & 5 \\
\hline S15 & JD 1510E & Russia, Karelia & 0.22 & pulpwood, sawlogs & spruce & $3-6$ \\
\hline S16 & JD 1510E & Finland, North Karelia & 0.17 & pulpwood & birch & $3-3.5$ \\
\hline S17 & Komatsu 845 & Finland, North Karelia & 0.19 & sawlogs & spruce & $4.3-5.5$ \\
\hline S18 & JD 1210 & Russia, Karelia & 0.17 & sawlogs & spruce & 3.5 \\
\hline S19 & Ponsse Elk & Russia, Karelia & 0.40 & sawlogs & spruce & 4.5 \\
\hline S20 & Ponnse Elephant King & Russia, Karelia & 0.22 & sawlogs & spruce & average 5 (4.5-5.5) \\
\hline S21 & Komatsu 895 & Sweden, Norrbotten & 0.09 & pulpwood & spruce & 4 \\
\hline
\end{tabular}

studied were characterized by flat relief and dry soils. All plots were located in areas of boreal coniferous forest of northern Europe. The surveyed sections of the trails, necessary for the full loading of the forwarder, did not have elevations that could affect the time and technology of loading. Logs in the forwarder's load space were folded in one row. Operation of the following forwarder models was considered: Ponsse Buffalo, Ponsse Elk, John Deere 1910E, 1910G, John Deere 1510E, John Deere 1210E, Ponsse Elephant King, Komatsu 845, Komatsu 895. Conventional control system (CBC) was used on the forwarders. A description of the operating conditions is presented in Table 1.

The duration of the elements of the manipulator's technological cycle was measured on the obtained video fragments, using a stopwatch, when the forwarder was loaded on a skid trail. The time of each time segment of the technological cycle was recorded with an accuracy of 0.01 seconds, and then the time was rounded up to 0.5 seconds. In the structure of the technological cycle of the manipulator, the following elements were considered, for which the time was recorded:

$\Rightarrow$ movement of the links of the empty manipulator.

The time was counted from the moment when the links of the manipulator began to move from the load space until the moment when the grapple touched the logs lying on the ground. There were special episodes during these periods of empty movements of the manipulator, such as: removal of branches and twigs that interfered with the capture of logs; sorting and moving individual logs without loading them; other techniques. The total number of such episodes and their duration were noted

$\Rightarrow$ movement of the manipulator links with the captured assortments. The time was counted from the moment the grapple touched the logs lying on the ground until the moment the grapple jaws opened when the logs were unloaded inside the load space of the forwarder. Special episodes were also noted within these time intervals

$\Rightarrow$ two commonly used techniques were re-grabbing logs and pulling of an incompletely closed log grip through the logs when the ends of the grabbed logs tilt and abut against the ground. The total number of such episodes and the duration of each loaded motion of the manipulator, which included such episodes, were determined $\Rightarrow$ other frequently occurring techniques observed within the loaded movements were intense multiple incomplete opening and closing of the grappling jaws while holding the logs with the grapple. This technique was commonly used to free the grab from accidentally picked up debris 
$\Rightarrow$ additional manipulator operations inside the load space of the forwarder. These operations included operations that fell in the interval from the opening of the grapple jaws when unloading logs in the load space until the next empty. Additional operations included moving, compacting and leveling logs inside the load space. The total number of such additional operations and their duration were determined.

Sequence of time intervals of elements of the technological cycle of the manipulator were obtained during the forwarders loading. One sequence described the loading cycle of one load space of one forwarder and formed one sample. A total of 21 samples were obtained for 9 different forwarder models (Table 2).

Time intervals were recorded, starting from the first empty to the last loaded movement of the manipulator, until the load space of the forwarder was completely full. The elements of the working cycle of the forwarder, in which there was no movement of the manipulator, were not investigated, for example, such as the movement of a fully loaded forwarder to the unloading area, the movement of the forwarder along the skid trail between stops during loading, the maneuvers of the forwarder on the skid trail and others. Also, the elements of the manipulator's work that are not related to the loading of assortments were not considered, for example, the work of the manipulator to strengthen the trails with logging residues and others.

The obtained samples of time intervals were processed using the methods of mathematical statistics. For each sample, a set of descriptive statistics parameters were determined: mean, standard deviation, median, mode and percentiles ( $25 \%$ and $75 \%$ ). The samples were checked for compliance with the normal distribution. For verification, the Pearson chi-square test was used.

Statistical analysis was performed for:

$\Rightarrow$ complete samples, consisting of time segments of empty and loaded movements of the manipulator (excluding time intervals attributable to additional movements of the manipulator inside the load space)

$\Rightarrow$ samples that consisted only of time segments of empty movements of the manipulator

$\Rightarrow$ samples that consisted only of time segments of the manipulator's loaded movements.

Further, the samples were checked for belonging to the same general population. For samples that corresponded to the characteristics of a normal distribution, the use of parametric tests was assumed, such as one-way analysis of variance (ANOVA) for independent measurements and Student's $t$-test, and the use
Table 2 Distribution of samples by forwarder models

\begin{tabular}{|l|c|c|}
\hline \multicolumn{1}{|c|}{ Model } & $\begin{array}{c}\text { Number } \\
\text { of samples }\end{array}$ & $\begin{array}{c}\text { Number } \\
\text { of operators }\end{array}$ \\
\hline John Deere 1910E-1910G-1510E-1210 & $4-4-2-1$ & $1-3-2-1$ \\
\hline Ponsse Buffalo-Elk-Elephant King & $6-1-1$ & $6-1-1$ \\
\hline Komatsu 845-895 & $1-1$ & $1-1$ \\
\hline
\end{tabular}

of the Leuven test was assumed to check the homogeneity of variances. Otherwise, as well as for small samples, the use of nonparametric tests was assumed: Kruskal-Wallis $H$-test and Mann-Whitney $U$-test (Spinelli et al. 2014, Prinz et al. 2018). Stadia 8.0, Excel programs were used to perform statistical analysis.

The samples were grouped to check the samples for belonging to the same general population. The main criterion for the grouping was the machine model; the auxiliary criterion was the average dimensions of the loaded assortments. When grouping the samples obtained from different forwarder models, the grouping was carried out according to the criterion of engine power and the rated carrying capacity of the machine. In this case, samples should have been obtained from machines of the same size (or close to it).

To perform statistical analysis, the samples were preliminarily combined into the following groups:

$\Rightarrow$ group No. 1: samples S1, S2, S3, S4, which were obtained from the work of the same operator on the same model of the John Deere 1910E machine

$\Rightarrow$ group No. 2: samples S5, S6, S7, S8 were obtained from the same model of the John Deere 1910G machine, but different operators worked on the forwarders

$\Rightarrow$ group No. 3: samples S9, S10, S11, S12, S13, S14 were obtained from the same model of the machine (Ponsse Buffalo), but with different operators

$\Rightarrow$ group No. 4: samples S15, S16 were obtained from the same model of the John Deere 1510E machine

$\Rightarrow$ group No. 5: samples S17, S18, S19 were obtained from different models of machines, but included in the same size group in terms of power and carrying capacity (Komatsu 845, John Deere 1210 and Ponsse Elk, respectively, (carrying capacity 12-13 tons, power 140-156 kW))

$\Rightarrow$ group No. 6: selections S20, S21 different models of machines, but included in the same size group in terms of power and carrying capacity (Ponsse Elephant King and Komatsu 895, respectively, (carrying capacity 18-20 tons, power 200-210 kW)). 


\section{Results}

Samples consisting of a sequence of time intervals falling on all elements of the manipulator cycle: emp- ty movements, loaded movements and movements inside the load space are shown in Fig. 1. Time intervals are shown in the sequence in which they were observed during loading of the forwarder.
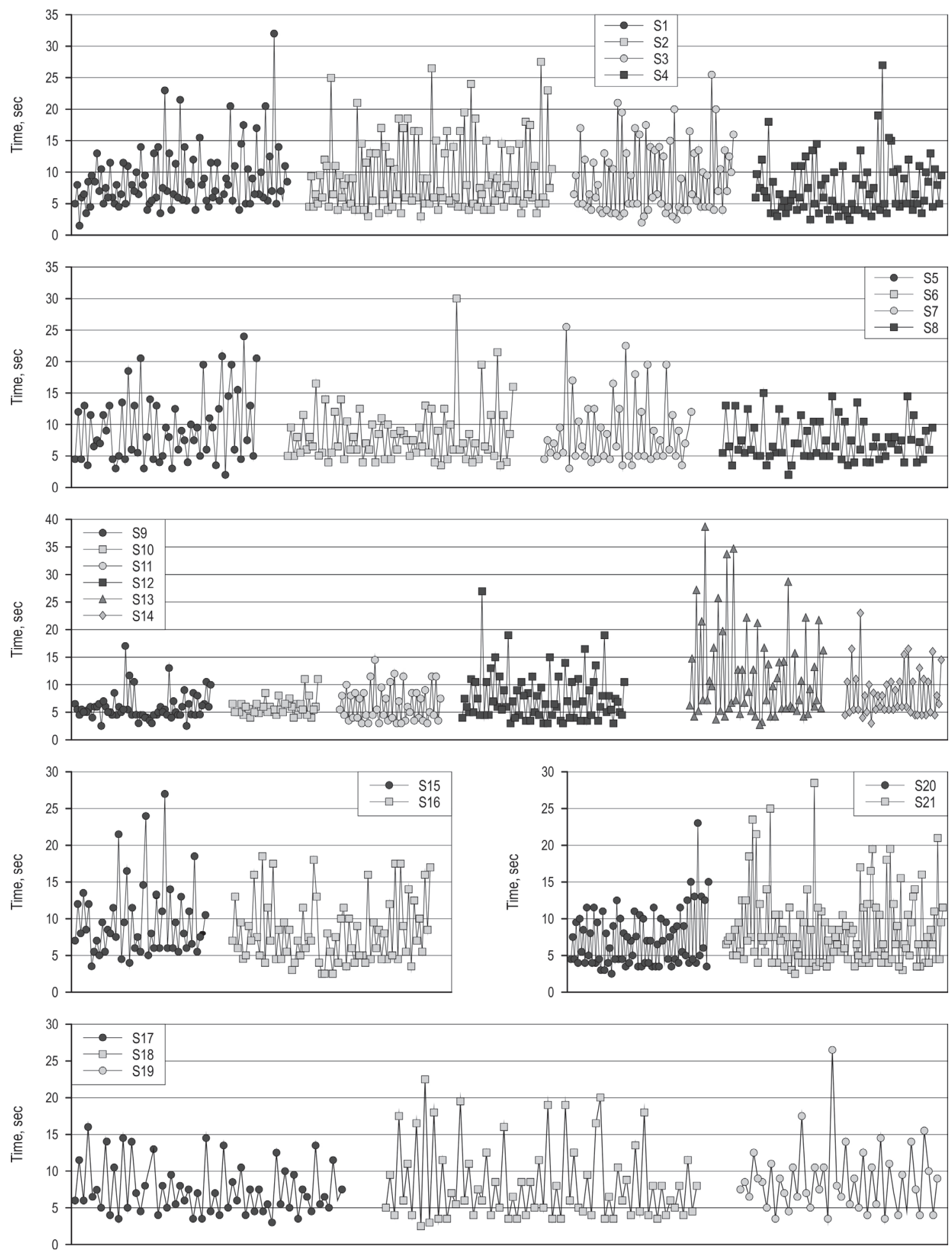

Fig. 1 Time segments of the manipulator cycle elements 
Table 3 General information about the technological cycle of the manipulator for each sample

\begin{tabular}{|c|c|c|c|c|c|}
\hline Sample & $\begin{array}{l}\text { Total time } \\
\text { sec. }\end{array}$ & $\begin{array}{c}\text { Number of loading cycles } \\
\text { (including unloading of single logs) }\end{array}$ & $\begin{array}{l}\text { Number of log } \\
\text { pieces }\end{array}$ & $\begin{array}{l}\text { Average number of loaded } \\
\text { movements per forwarder parking }\end{array}$ & $\begin{array}{l}\text { Average number of logs in a grapple } \\
\text { per one loaded movement }\end{array}$ \\
\hline S1 & 862 & 43 & 246 & 2 & 5.7 \\
\hline S2 & 1046 & 50 & 303 & $1.6^{1}$ & 6 \\
\hline S3 & 662 & 34 & 242 & $2.6^{1}$ & 7 \\
\hline S4 & 632 & 37 & 132 & $2.1^{1}$ & 3.6 \\
\hline S5 & 555.5 & 26 & 155 & 1.6 & 6 \\
\hline S6 & 604 & 34 & 134 & $-^{2}$ & 4 \\
\hline S7 & 421 & 23 & 149 & 2.3 & 6.5 \\
\hline S8 & 502 & 32 & 278 & 1.9 & 8.7 \\
\hline$\$ 9$ & 371.5 & 28 & 54 & 4 & 2 \\
\hline S10 & 238.5 & 20 & 60 & 1.8 & 3 \\
\hline S11 & 303 & 22 & 61 & 2.4 & 2.8 \\
\hline S12 & 579.5 & 32 & 89 & 2.9 & 2.8 \\
\hline S13 & 715.5 & 27 & 158 & 1.8 & 5.9 \\
\hline S14 & 376.5 & 22 & 49 & 4.4 & 2.2 \\
\hline S15 & 469 & 22 & 75 & $4.4^{1}$ & 3.4 \\
\hline S16 & 602 & 31 & 114 & 2.2 & 3.7 \\
\hline S17 & 464.5 & 30 & 95 & 3.8 & 3.2 \\
\hline S18 & 591 & 35 & 150 & $1.5^{1}$ & 4.3 \\
\hline S19 & 396 & 20 & 24 & 2.5 & 1.2 \\
\hline S20 & 564 & 38 & 98 & 2.7 & 2.6 \\
\hline S21 & 1043.5 & 59 & 423 & $-{ }^{2}$ & 7.2 \\
\hline
\end{tabular}

${ }^{1}$ We did not take into account the episodes when the forwarder did not remain motionless in the process of picking up logs by the manipulator and delivering them to the load space ${ }^{2}$ Simultaneously with the movement of the manipulator links when loading the logs, the forwarder slowly moved forward in all loading cycles

Information on the total time of the technological cycle of the manipulator, the total number of loaded assortments and the number of loading cycles for each sample are presented in Table 3. Fig. 2 shows for each sample the share of the total time spent separately for each element of the cycle, from the total time of the entire cycle of the manipulator.

In the obtained samples, the total time of loaded movements takes a share of 51 to $72 \%$ of the total operating time of the manipulator. The total time of empty movements of the manipulator ranges from 20 to $45 \%$ of the total time. In $80 \%$ of the samples, the time for empty movements takes from $26 \%$ to $36 \%$ of the total time.

Total time spent on the movement of the manipulator inside the load space while loading the forwarder ranges from 0 to $18 \%$ of the total loading time. If we exclude the lower and upper outliers from the samples, then $80 \%$ of the values fall in the range of $3-12 \%$.

Time, in which episodes were noted, where special methods of work were used, is in the range of $13-64 \%$ of the total time of loaded movements. The number of episodes with the use of special techniques varies, in the obtained samples, from 2 to 26 pieces (or from 10

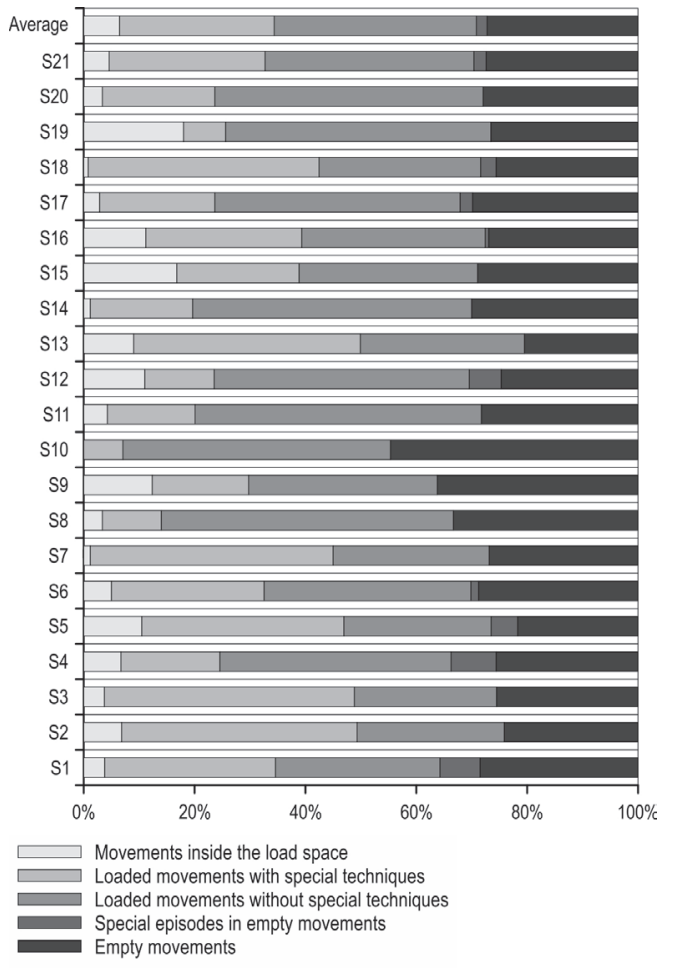

Fig. 2 Ratio of duration of individual elements in the general structure of the manipulator cycle 
to $53 \%$ of the total number of loaded moves). The average time spent on one loaded movement, in which special techniques were applied, was 15 seconds (range from 8 to 24 seconds).

The tests demonstrated that the sampling distributions are not normally distributed. Results of checking complete samples for belonging of samples in groups of the same general population are presented in Table 4. During the check, the values of time intervals related to the movements of the manipulator during operations inside the load space were excluded from the samples.

Table 4 Statistics tests (full samples)

\begin{tabular}{|c|c|c|c|c|}
\hline \multirow[b]{2}{*}{ Group } & \multirow[b]{2}{*}{ Samples } & \multicolumn{3}{|c|}{ Tests } \\
\hline & & $\begin{array}{c}\text { Kruskal- } \\
\text { Wallis } \\
\text { H-statistic }\end{array}$ & $\begin{array}{l}\text { Mann- } \\
\text { Whitney } \\
\text { z-score }\end{array}$ & $p$-value \\
\hline \multirow{2}{*}{1,2} & S1, S2, S3, S4 & 8.31 & - & 0.081 \\
\hline & S5, S6, S7, S8 & 1.44 & - & 0.697 \\
\hline 3 & $S 9, S 10, S 11, S 12$ & 5.08 & - & 0.166 \\
\hline 4 & S15, S16 & - & 1.291 & 0.197 \\
\hline 5 & S17, S18, S19 & 0.84 & - & 0.65 \\
\hline 6 & S20, S21 & - & 1.297 & 0.19 \\
\hline
\end{tabular}

Checking the samples of group 1 showed that they belong to the same general population. Checking the samples of group 2 also showed that these samples belong to the same population. In addition, checking the samples of group 1 and 2 with each other showed that these samples also belong to the same population.

Testing the samples of group 3 initially showed that these samples do not belong to the same population. The samples S13 and S14 were excluded from consideration according to the second criterion, i.e. the average diameter of the logs being loaded. Rechecking showed that samples S9, S10, S11 and S12 belong to the same population. Checking the samples from the remaining groups also showed that the samples within the groups belong to the same general population.

We tested the hypothesis that the samples of group 1 and 2 belong to the same general population together with the samples of group 6, since the forwarder models for these groups belong to the same size series. The check showed differences between the samples.

Since the complete samples do not belong to the normal distribution, the general statistical characteris-
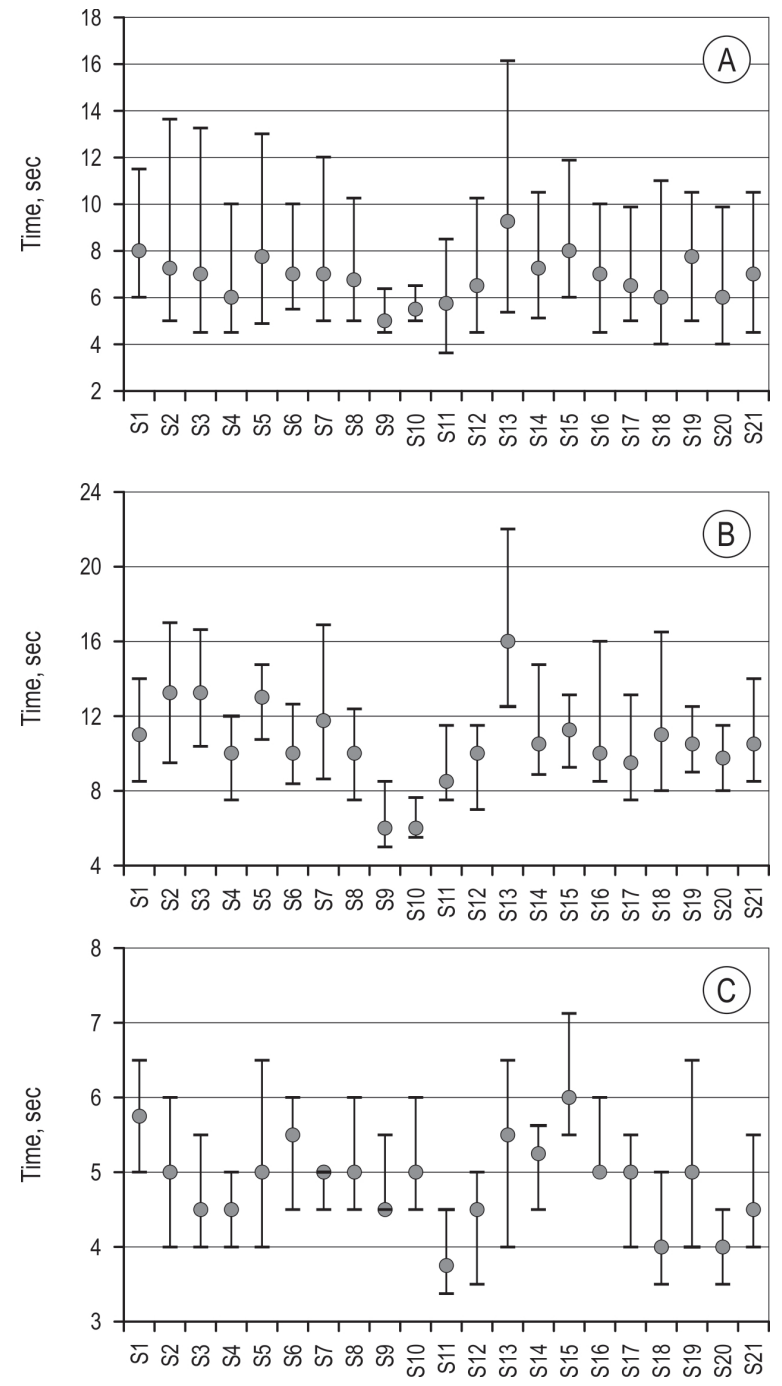

Fig. 3 Descriptive statistics for samples (medians and percentiles)

tics for the samples are represented by the median and percentiles (25\% and $75 \%$ ). Descriptive statistics for full samples are shown in Fig. 3A.

Medians of the full samples are between 4.5 and 9 seconds $(80 \%$ of the values fall between 6 and 8 seconds). The smallest interquartile range is 1.5 seconds; the largest is 10.8 seconds ( $80 \%$ of the range falls within the range of 4.5 to 8.8 seconds).

Checking samples, made of only loaded movements on belonging to one population, showed that in the combined group, made of samples of group 1 and 2 , the samples belong to the same population: $\mathrm{S1}, \mathrm{S} 2$, S3, S5 and S7 (Table 5). The rest of the samples (S4, S6, S8) do not belong to the same population. In group 3, samples S9 and S10 belong to the same population, as well as samples S11 and S12; however, there are differences between these pairs. Checking the rest of the 
Table 5 Statistics tests (samples of loaded movements)

\begin{tabular}{|c|c|c|c|c|}
\hline \multirow{2}{*}{ Group } & \multirow{2}{*}{ Samples } & \multicolumn{3}{|c|}{ Tests } \\
\cline { 3 - 5 } & & $H$-statistic & z-score & $p$-value \\
\hline 1,2 & S1, S2, S3, S5 S7 & 6.87 & - & 0.143 \\
\hline \multirow{2}{*}{3} & S9, S10 & - & -0.24 & 0.81 \\
\cline { 2 - 5 } & S11, S12 & - & 0,537 & 0.59 \\
\hline 4 & S15, S16 & - & 0.090 & 0.928 \\
\hline 5 & S17, S18, S19 & 2.80 & - & 0.246 \\
\hline 6 & S20, S21 & - & 0.868 & 0.38 \\
\hline
\end{tabular}

samples showed that within groups 4,5 and 6 , the samples belong to the same general population.

The medians of »loaded « samples are in the range between 6 and 16 seconds ( $80 \%$ of the values fall in the range between 8.5 and 13.25 seconds). The smallest interquartile range is 2 seconds; the largest is 9.5 seconds $(80 \%$ of the range falls within the $3.5-8$ seconds range). Descriptive statistics for «loaded» samples are shown in Fig. 3B.

Verification of samples composed of only empty movements of the manipulator for belonging to the same population showed that within the combined group 1 and 2, samples S2, S4, S5, S8 belong to the same population, while samples S3 and S7 belong to a different population (Table 6). Sample S6 was excluded from the analysis, since, unlike other samples, the empty movement of the manipulator in most cases began at the moment when the forwarder had not completely stopped and continued to slowly move forward. In group 3, there are differences between pairs of samples S9, S10 and S11, S12. In groups 4, 5 and 6 there are differences between the samples. Checking the loaded and empty samples for normality showed that some samples are distributed nor-

Table 6 Statistics tests (samples of empty movements)

\begin{tabular}{|c|c|c|c|c|}
\hline \multirow{2}{*}{ Group } & \multirow{2}{*}{ Samples } & \multicolumn{3}{|c|}{ Tests } \\
\cline { 3 - 5 } & & $H$-statistic & z-score & $p$-value \\
\hline \multirow{2}{*}{1,2} & S2, S4, S8, S5 & 5.9 & - & 0.116 \\
\cline { 2 - 5 } & S3, S7 & - & -0.656 & 0.509 \\
\hline \multirow{2}{*}{3} & S9, S10 & - & -1.526 & 0.126 \\
\cline { 2 - 5 } & S11, S12 & - & 1.751 & 0.08 \\
\hline
\end{tabular}

In groups 4, 5 and 6 there are differences between the samples mally, but due to the fact that the samples size is very small, the results of tests using nonparametric methods were used to make final conclusions about the belonging of the samples to the same general population.

The medians of »empty « samples are in the range between 3.75 and 6 seconds ( $80 \%$ of the values fall in the range between 4.5 and 6 seconds). The smallest interquartile range is 0.5 seconds; the largest is 2.5 seconds ( $80 \%$ of the range falls within the range of $1-2$ seconds). Descriptive statistics for »empty « samples are shown in Fig. 3C.

\section{Discussion}

Studies have confirmed that the operation of a manipulator can be viewed as a separate technological process within the forwarder's technological process. This technological process consists of both individual operations and special techniques that are used when performing operations. The fact is that individual manipulator operations make different contributions to the total operating time of the manipulator, which is confirmed, among other things, by the studies of Berg et al. 2017 and Kaleja et al. 2017.

When the forwarder is working in clearcutting after the harvester, the time of one working cycle of the manipulator, including one loaded motion and one empty motion, falls within the range of 4-14 seconds, with a probability of $95 \%$. These data, summarized for all samples, are consistent with the data for samples collected only from the work of one operator (samples S1, S2, S3, S4).

The results show that, other things being equal, the elements of the manipulator operation cycle are affected by: standard size (power) characteristics of the forwarder. Samples obtained for machines of different standard sizes have discrepancies when comparing full samples with each other. However, the question of the influence of the forwarder model remains open, since the samples obtained for machines of the same standard size, but produced by different companies, have discrepancies and do not belong to the same general population. More extensive collection of experimental data is required to confirm this effect.

In obtained samples, the standard size of the machine does not have a strong influence, but affects the average time of one working cycle of the manipulator (a pair of loaded and empty). Comparing the average medians obtained in each size group of forwarders, the time of one pair of empty-loaded movements decreased by 1 second, and by 2 seconds when considering 

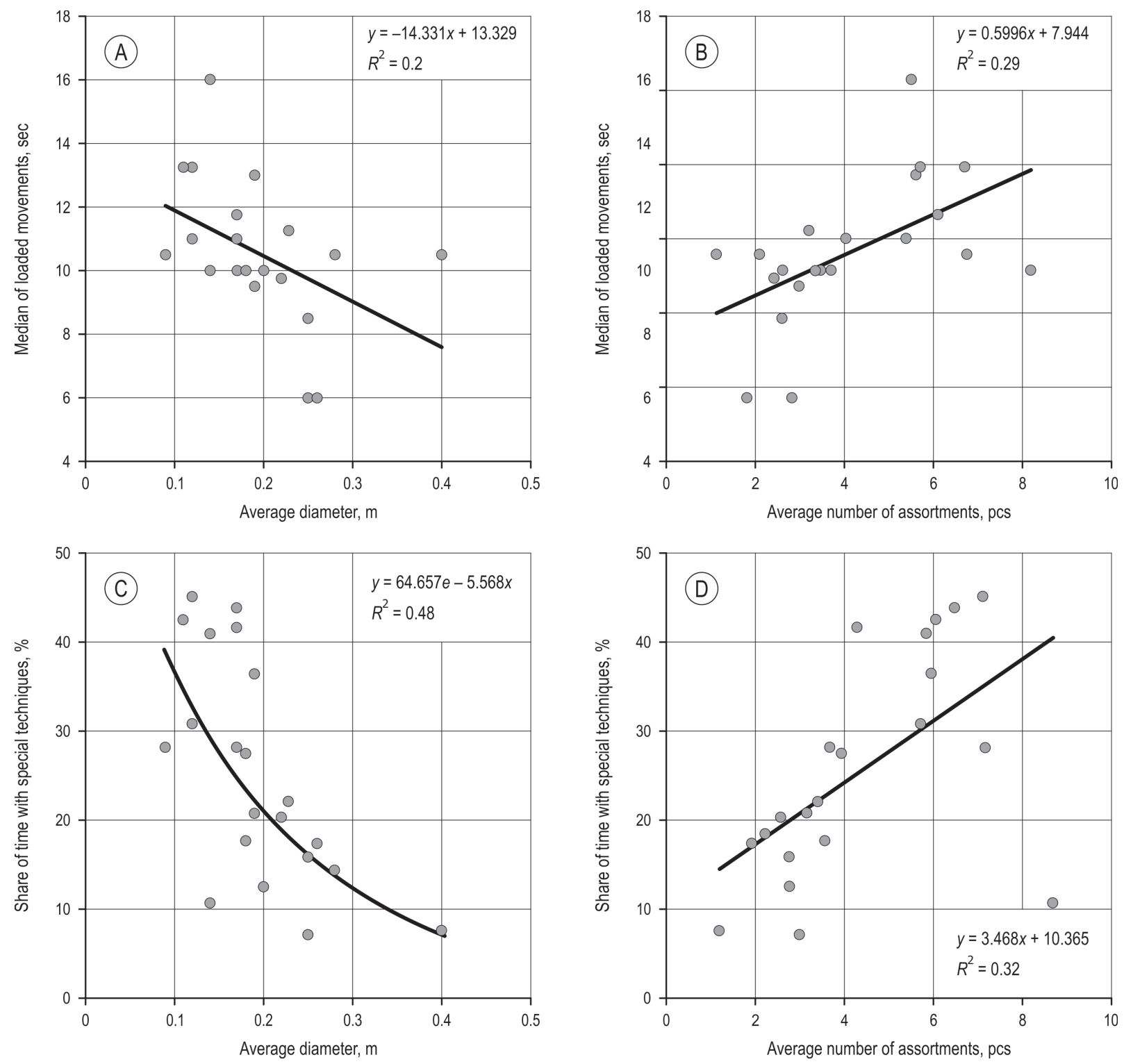

Fig. 4 Influence of assortment sizes on manipulator loaded movements

only the loaded movement of forwarders with higher power. However, for a better analysis, additional experimental data is required, especially for machines with a power of less than $164 \mathrm{~kW}$.

The elements of the manipulator technological cycle are influenced by the average diameter of the assortments. This influence was reflected in the discrepancy between the samples collected in the study of the operation of forwarders of the same model (sample group No. 3) loaded with assortments with different average diameters, as well as in the presence of a correlation between the median time intervals of loaded movements and the average diameter of the assortments (Fig. 4A). Additional factor in favor of this influence is the presence of a correlation between the average number of assortments in the capture per one loaded movement and the median of time intervals of loaded movements (Fig. 4B). With an increase in the number of assortments, the median increases linearly.

In addition, within the groups (groups No. 1 and $2)$, there is a discrepancy between the individual samples, which were collected in time intervals of loaded movements. This is due to the influence of the special techniques that the operators used during the loading process. If the proportion of time spent on movements in which special techniques were used in the sample is less than $30 \%$ of the total time (S4, S6, S8), then such samples differ from the samples (S1, S2, S3, S5, S7), in 
which the share of the time of movements with techniques is more than $30 \%$ (or more than $50 \%$ of the total time of loaded movements). The less the proportion of time spent on movements with special techniques, the closer the distribution law of time intervals to the normal law.

The primary factor in the collected samples that affects the total time of loaded movements with special techniques is the average diameter of the assortments. As the average diameter increases, the number of special techniques decreases. In the present study, a close relationship was found between the average diameter of the assortments and the total time of loaded movements, where special techniques were used. This relationship is exponential (Fig. 4C). Also, the value of the time of movements with special techniques is influenced by the average number of assortments carried in the grapple per one loaded move. Here, the nature of the connection is linear (Fig. 4D).

Total time of loaded movements (including the capture of logs) in the obtained data takes $51-72 \%$ of the total operating time of the manipulator, which is generally consistent with the results of other studies 54-71\% (Berg et al. 2017, Kaleja et al. 2017). There are some differences between the experimental data obtained and the results presented by Cadei et al. (2020). These differences can be explained by the fact that the authors studied the technological cycle of the forwarder during emergency logging in hard-to-reach areas. The results presented in this article were obtained in conditions not characterized by emergency and difficult to access situations.

Analysis of samples made of intervals of empty moves showed the discrepancy of these samples within separate groups. The following pattern was found: the discrepancy was observed in the case where there was a difference between the samples in the average number of loaded cycles of a manipulator performed at one working parking of the forwarder. Samples S2, $\mathrm{S} 4, \mathrm{~S} 8$, S5, the number of loaded cycles from one parking lot throughout the entire loading process was 1-2 cycles, and for samples S3 and S7 2-3 cycles. For S15 sampling, $4-5$ cycles, and for $\$ 16$ sampling, 2-3 cycles. For S17 sampling 3-4 cycles; samples S18 1-2; S19 2-3. Weak correlation shows an increase in the median of the sample of time intervals of empty movements with an increase in the number of working cycles per one forwarder parking. However, this hypothesis requires additional testing on the basis of larger experimental data. The discrepancy between the samples in some cases (samples S21, S6) is explained by the fact that most of the empty motions during loading were carried out in the slow motion of the forwarder. At the same time, it is obvious that there is no correlation between the average diameter and the median of the time intervals of empty movements.

Total time of empty is 20 to $45 \%$ of the total manipulator operating time when loading the forwarder. In other studies, this time is on average 20-26\% (Berg et al. 2017, Kaleja et al. 2017).

Duration of the episodes associated with the manipulator operation inside the load space in the studied experiments varied from 0 to $18 \%$ of the total manipulator operation time (on average, $7 \%$ ). In other studies, these periods were about 5\% and 20\% (Berg et al. 2017), as well as 14\% (Apafaian et al. 2017). Close relationship between the average diameter of the assortments and the time spent on movements inside the load space was not found, nor was it found between the time of these movements and the average number of assortments loaded per one loaded movement of the manipulator.

The presence of a range of values within the collected samples of time intervals of empty and loaded movements of the manipulator can be explained by the influence of factors not considered in this study. Such hypothetical factors influencing the loading of forwarders may be as follows:

$\Rightarrow$ placement of assortments relative to the skid trail. The distance between the logs and the forwarder can be variable, as can the size of the stacks of logs at each working parking for the forwarder. In the present study, data were collected when the forwarders were working after the harvesters, but the location of the logs could be different in relation to the skid trails in different felling areas. The fact that the arrangement of the assortments affects the loading times of forwarders is indirectly confirmed by the studies of Laitila et al. 2007, Danilović et al. 2014

$\Rightarrow$ qualification of harvester operators. Loading logs onto the forwarder can be difficult due to errors in placing the logs on the ground after harvester operations

$\Rightarrow$ individual psychological personality traits of forwarder operators and operator fatigue. Although the experiments were conducted with experienced operators, the factor related to operator fatigue was not considered. The human factor as a factor influencing the time of efficient operation of forestry machines has been studied in works of Lamminen et al. 2011, Lutsenko et al. 2008, Malinen et al. 2018, Mehrentsev et al. 2007, Purfürst and Erler 2011. 


\section{Conclusions}

The data collected under different conditions show the presence of general patterns in the structure of the technological cycle of the manipulator. In the technological cycle of the manipulator, there are three main elements: loaded movements; empty movements and movements of the manipulator when performing operations inside the load space. On average, $63 \%$ of the technological cycle of the manipulator falls on loaded movements; $30 \%$ for empty and $7 \%$ for operations performed inside the load space. With a $95 \%$ degree of probability in the studied production conditions, the time of one loaded movement falls within the range of 4-14 seconds, and one empty motion in the range of 3-7 seconds.

Different elements of the manipulator cycle are influenced by different factors. The use of special techniques by the operator has a significant impact on loaded movements. The most influential techniques are: re-gripping logs and pulling of an incompletely closed log grip through the logs when the ends of the grabbed logs tilt and abut against the ground. Proportion of loaded movements in which the operator uses special techniques can be over $50 \%$ of the total number of loaded moves and over $60 \%$ of the time of the total time of loaded movements. The number and duration of loaded moves with these techniques is significantly influenced by: the average size of the assortments and the number of assortments carried in the grapple during one loaded movement. Some reduction in the share of these methods can be achieved by rational methods of stacking assortments during the work of the harvester. There is some influence of the standard size of the machine on the time of one loaded movement.

No significant influence of the average size of the assortments, the number of assortments in the grapple, the standard size of the machine on empty movements was found. However, the influence of the average number of loading cycles from one parking lot of the forwarder on empty movements was observed. The duration and frequency of operations inside the load space are weakly correlated with the size of the assortments and the size of the forwarder. The author admits that, with an increase in the amount of experimental data and the inclusion of unaccounted factors in the study, the conclusions made and the patterns identified in the present study can be adjusted and clarified.

\section{References}

Apăfăian, A.I., Proto, A.R., Borz, S.A., 2017: Performance of a mid-sized harvester-forwarder system in integrated harvesting of sawmill, pulpwood and firewood. Ann For Res 60(2): 227-241. https://doi.org/10.15287/afr.2017.909
Berg, S., Yoshida, M., Sakurai, R., Sakai, H., 2017: Comparison of productivity and cost depending on slope when forwarding short length logs with small Japanese forwarders. Int J For Eng 28(3): 176-185. https://doi.org/10.1080/14942119.201 7.1358550

Cadei, A., Mologni, O., Röser, D., Cavalli, R., Grigolato, S., 2020: Forwarder productivity in salvage logging operations in difficult terrain. Forests 11(3): 341. https://doi.org/10.3390/ f11030341

Danilović, M., Stojnić, D., Karić, S., Sučević, M., 2014: Transport of technical roundwood by forwarder and tractor assembly from poplar plantations. Nova meh šumar 35(1): 11-22.

Dvořák, J., Malkovský, Z., Macků, J., 2008: Influence of human factor on the time of work stages of harvesters and crane-equipped forwarders. J For Sci 54(1): 24-30. https://doi. org/10.17221/790-JFS

Ghaffarian, M.R., Stampfer, K., Sessions, J., 2007: Forwarding productivity in Southern Austria. Croat J For Eng 28(2): 169174.

Hildt, E., Leszczuk, A., Donagh, P., Schlichter, P., 2019: Time consumption analysis of forwarder activities in thinning. Croat J For Eng 41(1): 13-24. https://doi.org/10.5552/crojfe.2020.615

John Deere Intelligent Boom Control. Available online: https://www.youtube.com/watch?v=5TWBkxx7TD8 (Accessed 10 May, 2020).

Kaleja, S., Zimelis, A., Lazdins, A., Johansson, P.O., 2017: Comparison of productivity of Kranman Bison 10000 forwarder in stands harvested with harvester and chainsaw. Proceedings of the $8^{\text {th }}$ International Scientific Conference Rural Development, Kaunas, Lithuania, 23-24 November. http://doi.org/10.15544/RD.2017.199

Lamminen, S., Väätäinen, K., Asikainen, A., 2011: The importance of the forwarder operator in loading phase during virtual CTL-forwarding. Proceedings of the $44^{\text {th }}$ International Symposium on Forestry Mechanisation: «Pushing the Boundaries with Research and Innovation in Forest Engineering», Graz, Austria, 9-13 October.

La Hera, P., Ortiz Morales, D., 2019: What do we observe when we equip a forestry crane with motion sensors? Croat J For Eng 40(2): 259-280. https://doi.org/10.5552/crojfe.2019.501

Laitila, J., Asikainen, A., Nuutinen, Y., 2007: Forwarding of whole trees after manual and mechanized felling bunching in pre-commercial thinnings. Int J For Eng 18(2): 29-39. https://doi.org/10.1080/14942119.2007.10702548

Lundbäck, M., Häggström, C., Nordfjell, T., 2018: Worldwide trends in the methods and systems for harvesting, extraction and transportation of roundwood. Proceedings of the $6^{\text {th }} \mathrm{In}$ ternational Forest Engineering Conference »Quenching our thirst for new Knowledge«, Rotorua, New Zealand, 16-19 April.

Lutsenko, E., Ryabukhin, P., Abramenko, A., 2008: On the issue of efficient increase of logging machines. Bulletin of PNU 1(8): 183-188. 
Malinen, J., Laitila, J., Väätäinen, K., Viitamäki, K., 2016: Variation in age, annual usage and resale price of cut-tolength machinery in different regions of Europe. Int J For Eng 27(2): 95-102. https://doi.org/10.1080/14942119.2016.1171964

Malinen, J., Taskinen, J., Tolppa, T., 2018: Productivity of cutto-Length harvesting by operators' age and experience. Croat J For Eng 39(1): 15-22.

Manner, J., Gelin, O., Mörk, A., Englund, M., 2017: Forwarder crane's boom tip control system and beginner-level operators. Silva Fenn 51(4): 1717. https://doi.org/10.14214/sf.1717

Manner, J., Nordfjell, T., Lindroos, O., 2013: Effects of the number of assortments and log concentration on time consumption for forwarding. Silva Fenn 47(4): 1030. http:// dx.doi.org/10.14214/sf.1030

Manner, J., Palmroth, L., Nordfjell, T., Lindroos, O., 2016: Load level forwarding work element analysis based on automatic follow-up data. Silva Fenn 50(3): 1546. https://doi. org/10.14214/sf.1546

Mehrentsev, A., Beljajkov, F., Polukarov, M., 2007: Estimation of harvester operator shift duration influence over productivity and enviromental condition. Forestry Bulletin 8: 130-132.

Moskalik, T., Borz, S.A., Dvořák, J., Ferencik, M., Glushkov, S., Muiste, P., Lazdiṇš, A., Styranivsky, O., 2017: Timber harvesting methods in eastern European countries: A review. Croat J For Eng 38(2): 231-241.

Nurminen, T., Korpunen, H., Uusitalo, J., 2006: Time consumption analysis of the mechanized cut-to-length harvesting system. Silva Fenn 40(2):335-363. https://doi.org/10.14214/ sf.346

Ortiz Morales, D., Westerberg, S., La Hera, P.X., Mettin, U., Freidovich, L., Shiriaev, A.S., 2014: Increasing the level of automation in the forestry logging process with crane trajectory planning and control. J Field Robot 31(3): 343-363. https://doi.org/10.1002/rob.21496

Prinz, R., Spinelli, R., Magagnotti, N., Routa, J., Asikainen, A., 2018: Modifying the settings of CTL timber harvesting machines to reduce fuel consumption and $\mathrm{CO}_{2}$ emissions. $\mathrm{J}$
Clean Prod 197: 208-217. https://doi.org/10.1016/j. jclepro.2018.06.210

Proto, A.R., Macrì, G., Visser, R., Harrill, H., Russo, D., Zimbalatti, G., 2017: A case study on the productivity of forwarder extraction in small-scale Southern Italian forests. SmallScale For 17(1): 71-87. https://doi.org/10.1007/ s11842-017-9376-Z

Proto, A.R., Macrì, G., Visser, R., Harrill, H., Russo, D., Zimbalatti, G., 2018: Factors affecting forwarder productivity. Eur J Forest Res 137(2): 143-151. https://doi.org/10.1007/s10342017-1088-6

Purfürst, F.T., Erler, J., 2011: The human influence on productivity in harvester operations. Int J For Eng 22(2): 15-22. https://doi.org/10.1080/14942119.2011.10702606

Puttock, D., Spinelli, R., Hartsough B.R., 2005: Operational trials of cut-to-length harvesting of poplar in a mixed wood stand. Int J For Eng 16(1): 39-49. https://doi.org/10.1080/1494 2119.2005.10702506

Smirnov, M., Bakulina, I.,R., 2013: Wall-mounted hydraulic manipulator work cycle time. Vestnik of Volga State University of Technology. Series »Forest. Ecology. Nature management « 3(19): 72-81.

Spinelli, R., Lombardini, C., Magagnotti, N., 2014: The effect of mechanization level and harvesting system on the thinning cost of Mediterranean softwood plantations. Silva Fenn 48(1): 1003. https://doi.org/10.14214/sf.1003

Spinelli, R., Magagnotti, N., Picchi, G., 2011: Annual use, economic life and residual value of cut-to-length harvesting machines. J Forest Econ 17(4): 378-387.http://dx.doi.org/10.1016/j. jfe.2011.03.003

Stankić, I., Poršinsky, T., Tomašić, Z., Tonković, I., Frntić, M., 2012: Productivity models for operational planning of timber forwarding in Croatia. Croat J For Eng 33(1): 61-78.

Strandgard, M., Mitchell, R., Acuna, M., 2017: Time consumption and productivity of a forwarder operating on a slope in a cut-to-length harvest system in a Pinus radiata D. Don pine plantation. J For Sci 63(7): 324-330. https://doi. org/10.17221/10/2017-JFS
Author's address:

Assoc. prof. Maxim Piskunov, PhD

e-mail: piskunov_mp@list.ru

Petrozavodsk State University

Institute of Forestry, Mining and Construction

Sciences

Lenin Str., 33

185910 Petrozavodsk

Republic of Karelia

RUSSIA 